\title{
Situational Correlates of Adolescent Substance Use: An Improved Test of the Routine Activity Theory of Deviant Behavior
}

\author{
Ellen de Jong ${ }^{1} \cdot$ Wim Bernasco ${ }^{2,3}$ D $\cdot$ Marre Lammers $^{2}$
}

Published online: 17 October 2019

(C) The Author(s) 2019

\begin{abstract}
Objectives To test the routine activity theory of deviance, we assess whether adolescents are most likely to use substances while they are involved in unstructured activities, in the presence of peers and in the absence of authority figures. We also test whether these situational factors interact.

Methods A time use instrument was applied to collect hour-by-hour information on activities and substance use from a sample of adolescents. To control for potential confounders, the effects of the three situational factors on substance use were estimated with fixedeffects logit models.

Results The findings show that adolescents' substance use takes place during unstructured activities, when peers are present, and when authority figures are absent, and that these situational factors are not strengthened by each other.

Conclusions Supporting the routine activity theory of deviance, we conclude that unstructured activity, peer presence and absence of authority figures are situational factors that facilitate substance use. In contrast to what the theory proposes, and relevant for parents and professionals, these factors function independently and need not all be present simultaneously for deviant behavior to occur.
\end{abstract}

Keywords Adolescents - Substance use - Routine activity theory of deviance · Criminological theory $\cdot$ Fixed effects logit

Electronic supplementary material The online version of this article (https://doi.org/10.1007/s 1094 0-019-09433-w) contains supplementary material, which is available to authorized users.

Wim Bernasco

wbernasco@nscr.nl; w.bernasco@vu.nl

1 Institute of Criminal Law and Criminology, Leiden University, Leiden, The Netherlands

2 Netherlands Institute for the Study of Crime and Law Enforcement (NSCR), P.O. Box 71304, 1008BH Amsterdam, The Netherlands

3 Department of Spatial Economics, Vrije Universiteit Amsterdam, Amsterdam, The Netherlands 


\section{Introduction}

Substance use among adolescents has been linked to negative physical, social, and psychological consequences (e.g. Gmel et al. 2003). Moreover, early initiation of substance use has been identified as an important marker of later substance use problems (Behrendt et al. 2009; King and Chassin 2007; Lynskey et al. 2003). These findings highlight the importance of understanding the etiology of substance use among adolescents. Much is known about individual differences between adolescents who do and who do not use alcohol and drugs [see for a review Flay and Petraitis (2003)] and about the prevalence of simultaneous use of alcohol and cannabis (Terry-McElrath et al. 2013). However, less is known about the differences between situations in which they use these substances and the situations in which they don't (Hussong 2000).

To explain what situations facilitate or provoke deviant behavior (e.g. substance use), the routine activity theory of deviance (Osgood et al. 1996) has been the dominant perspective in the literature. Like other opportunity theories of crime, in particular routine activity theory (Cohen and Felson 1979), crime pattern theory (Brantingham and Brantingham 1993) and rational choice theory (Cornish and Clarke 1986), it emphasizes situational conditions and criminal opportunities as proximal causes of crime. The theory identifies three situational elements that influence deviant behavior: unstructured activities, presence of peers, and absence of authority figures (Osgood et al. 1996).

Unstructured activities are activities that carry no agenda for how time is to be spent (e.g. hanging around). In structured activities, most time is spent in designated ways restricting the time available for substance use, whereas in unstructured activities the expectations about how time is spent are less fixed, which leaves opportunities and time for substance use. The presence of peers facilitates the use of substances by making it easier (e.g. alcohol availability), and by increasing the rewards in terms of enhanced status and reputation. Authority figures (e.g. parents) are individuals whose role in a situation accompanies a responsibility for exerting social control, thus their absence will reduce the risk of disapproval and sanctions. The combination of all three elements together is generally referred to as unstructured socializing.

The positive relationship between unstructured socializing and substance use has been widely supported (e.g. Augustyn and McGloin 2013; Barnes et al. 2007; Demers 1997), but the empirical evidence is characterized by two limitations.

First, a shortcoming of previous studies is that the relationship between unstructured socializing and substance use is only established at the level of the individual. It is rarely investigated at the level of the situation, which is the level at which it operates according to the theory. For example, is has been demonstrated that adolescents who spend more time with peers are more likely to use alcohol and drugs, but whether these adolescents use these substances during the time spent with peers is largely unknown. The same limitation applies to the two other situational elements: does substance use actually take place during unstructured activity and in the absence of authority figures? The few studies that did take a situational approach to investigate these questions focused on adults instead of adolescents (e.g. Demers 1997), addressed only effects of time spent with peers (Beier 2018), and were limited to alcohol use exclusively (Beier 2018; Demers 1997).

The second limitation of previous research is that it has rarely investigated the independent effects of the three elements that constitute unstructured socializing. Unstructured socializing is defined by a combination of attributes, i.e. as an unstructured activity during which peers are present and authority figures absent (Osgood et al. 1996). Most studies 
have thus combined multiple elements of unstructured socializing in a single item, for example by asking respondents about the amount of time they spend with friends without adults being present (e.g. Barnes et al. 2007; Flannery et al. 1999). This approach cannot distinguish between the effect of one situational element (e.g. presence of peers), the effect of the other element (e.g. absence of authority figures), and the effect of the simultaneous combination of both situational elements. Consequently, it has remained unclear whether unstructured activity, presence of peers, and absence of authority figures have independent effects, or whether their effects interact and are thus interdependent.

The present study aimed to resolve both limitations in the extant literature by examining at the situational level the relations between the elements of unstructured socializing and adolescent substance use. To that aim, we applied a dedicated time use instrument (Wikstrom and Butterworth 2006; Wikstrom et al. 2012) to systematically record how adolescents allocate their time to activities. Detailed hour-to-hour information about 4 days was collected amongst 868 adolescents aged 11-18 years. For reasons of analytical rigor, we focused on within-person variation across situations, and selected for analysis only the 229 individuals who reported substance use at least once during the 4-day data collection period. Our findings demonstrate that involvement in unstructured activities, presence of peers, and absence of authority figures provoke substance use. We provide evidence that these effects accumulate, but do not interact.

The key contribution of this paper is the combination of the unique situational data with an adequate statistical methodology to test the influence of situational elements on substance use, both separately and jointly. The results provide insight in the relative effects of unstructured activity, peer presence and authority absence on substance use. Intervention programs and policies might benefit from this knowledge as it may enable them to shift their attention to the specific situations that most strongly provoke the use of alcohol and drugs by adolescents.

\section{Routine Activity Theory of Deviant Behavior}

Even highly deviant people do not perform deviant behaviors all the time. To explain why a person is deviant in one situation but not in other situations, a situational perspective is required. In this perspective, it is not individual attributes and motivations that explain deviant behavior, but instead the conditions that stimulate or facilitate this behavior in particular situations. In criminology, the shift from the importance of individual attributes and motivations for behavior to opportunities for behavior was first made in social control theory (Hirschi 1969), and was developed further by routine activity theorists.

Routine activity theory first focused on the situational aspects in which victimization of predatory crime occurs (Cohen and Felson 1979), and later on the situational aspects of deviant behavior in general (Osgood et al. 1996). Two other theoretical perspectives that focus on situational factors and criminal opportunities are rational choice theory and crime pattern theory. Rational choice theory (Cornish and Clarke 1986) takes a micro-economic perspective, emphasizing that criminal decision-making, like many other behaviors, is subject to the calculus of expected costs and benefits of choice alternatives. While our theoretical framework is structured by the routine activity of deviant behavior, where deemed necessary or useful we will highlight how its concepts and arguments relate to the rational choice perspective. Crime pattern theory (Brantingham and Brantingham 1993) takes a multidisciplinary approach with a focus on the geometry of crime, spatial routines of 
offenders and criminogenic attributes of places. While highly relevant for understanding the geography of crime and deviant behaviors, the theory is less useful for understanding the situational aspects addressed in the present study. Therefore, it will not be used as a frame of reference in the present study.

The routine activity theory of deviant behavior (Osgood et al. 1996) assumes that both victimization and deviant behavior depend on opportunities available in the immediate situational context. This context consists of where an individual is, with whom, and what he or she is doing (Pervin 1978). The theory predicts deviant behavior (e.g., adolescent substance use) to take place when the deviant act is possible and rewarding. Osgood et al. (1996) assert that a situational context of unstructured socializing provokes deviant behavior, and identify three situational elements that jointly define unstructured socializing: unstructured activity, the presence of peers, and the absence of authority figures. Situations of unstructured socializing are thus situations in which all three conditions converge simultaneously in space and time.

\section{Unstructured Activities}

The idea that certain types of activities can influence deviant behavior originates from social control theory (Hirschi 1969). According to this theory, and in line with the rational choice theory that puts behavior incentives center stage, involvement in conventional activities (e.g. homework) is part of the social bond of an individual to conventional society (e.g. school), and can provide protection against deviance because it increases the costs of deviance. Besides an explanation for which individuals are most likely to be deviant, involvement in certain activities can provide an explanation in which situations a person does or does not display deviant behavior (e.g., use alcohol and/or drugs). At this situational level, involvement in conventional activities is considered a protective factor explained by the assumption that "a person might be too busy doing these conventional activities to find time and opportunities to engage in deviant behavior" (Hirschi 1969, p. 22). For example, in sports more time is spent in designated ways, restricting the time and opportunities available for substance use (Osgood et al. 1996). Unstructured activities, on the other hand, are considered risk factors for deviant behavior. Osgood et al. (1996) defined unstructured activities as activities that "carry no agenda for how time is to be spent" (p. 640). This definition covers activities that are not, or weakly, organized such as hanging around and visiting friends. For example, when visiting friends, generally the expectation about how time is spent is less fixed, leaving time and opportunities for substance use.

To the best of our knowledge, studies have not yet investigated the relationship between unstructured activities and substance use at the situational level, but only at the individual level. In line with theory, previous studies found that more time spent in unstructured activities is linked to more substance use (e.g. Miller 2013; Osgood et al. 1996). These studies looked at similar unstructured activities: evenings out for fun, going to parties, and driving around for fun. All studies found a positive relationship between substance use and these unstructured activities. For structured activities, previous research gave more attention to a variety of activities that could protect adolescents against alcohol and drug use. Time spent on homework (Barnes et al. 2007), work around the house and sports (Barnes et al. 2007; Miller 2013), cultural activities (Hawdon 1999; Miller 2013), and community activities (e.g. Anderson and Hughes 2009; Miller 2013) are all negatively associated with substance use. These studies combined seem to indicate that substance use is more likely during unstructured activities. Based on the above arguments and evidence, the first hypothesis 
asserts that adolescents are more likely to use substances during unstructured activities than during structured activities (H1).

\section{Presence of Peers}

The importance of peer influence on behavior has long been acknowledged, and is salient in adolescence (for a review see Brechwald and Prinstein 2011). A robust finding is that adolescents' behaviors and attitudes are remarkable similar to those of their friends (Brechwald and Prinstein 2011). This results from a combination of selection and socialization effects, which explain both about half of the similarity between behaviors and attitudes of friends (Kirke 2004; Petraitis et al. 1995). Selection effects refer to the tendency people have to associate with people who are similar in terms of behavior and attitudes. The selection effect is a precondition for the socialization process, which entails that behaviors and attitudes of adolescents and their friends become more similar over time.

In adolescents, friends might influence substance use in different directions. On the one hand, adolescents who have positive attitudes towards substance use are likely to associate with peers with similar norms (selection), and these peers may further facilitate substance use (socialization). On the other hand, friends who disapprove of substance use (e.g. friends from a sport club) may inhibit the behavior. Previous research confirms the encouraging effect of friends: more time spent with peers increases deviant behavior during adolescence (Warr 2002), a finding that also applies to alcohol consumption (Beier 2018). In line with this, we assume that peers support the use of substances and hence, the implicit assumption here is that people associate with others who have similar norms about substance use.

The physical presence of peers is the key to the mechanisms of peer influence (Hussong 2002). It can influence substance use of adolescents in at least two ways. First, presence of peers may facilitate substance use by making it easier, as peers play an important role in the availability of alcohol and drugs. Often adolescents' first contact with substances is through friends, and later on substances are also usually provided by friends (Moon et al. 1999; Osgood et al. 1996). In terms of rational choice theory, the presence of peers reduces the costs of getting access to alcohol or drugs. Second, presence of peers may facilitate substance use by increasing the rewards. The three most effective mechanisms that increase rewards of deviant behavior are fear of ridicule, display of loyalty, and status seeking (Warr 2002).

The first mechanism, fear of ridicule, emerges from the risk of rejection. Rejection by the group can lead to loss of identity and status. This fear of ridicule and rejection is specifically important for adolescents. The second mechanism, displaying loyalty, is closely related to the risk of rejection as mutual loyalty provides protection against rejection. Research shows loyalty in friendships is important for adolescents (Warr 1993). Finally, the literature shows that earning and maintaining status is a primary objective of group members. Deviant behavior can be considered a way to earn status (Warr 2002). In short, fear of ridicule, displaying loyalty, and status seeking can increase rewards of certain behavior that is dangerous or not desirable, i.e. substance use for adolescents.

Substance use can only confirm or improve status if peers are aware of the act. The same argumentation holds for fear of ridicule and display of loyalty (Warr 2002). As the focus of this study is on explaining the situations in which substances are used, the arguments only apply to those situations where peers are physically present. Status may be enhanced 
because friends are aware of substance use via other channels (e.g. Facebook), but this does not explain why substances are used in the physical presence of peers.

Besides the mere presence of peers, the number of peers present is important because additional peers affect both the costs and rewards associated with substance use. For example, status enhancement is greater if substance use is witnessed by many peers than when witnessed by only a single peer. Various experiments have shown that conformity to group pressure increases with group size (see for a review, Bond 2005). To conclude, presence of peers can increase both the opportunity for and the rewards of substance use.

Previous studies have extensively investigated the relationship between peers and substance use, and found that adolescents who spent more time with their peers use more substances (e.g. Barnes et al. 2007; Flannery et al. 1999). Two studies have examined this relationship at the situational level. They showed that in the presence of friends alcohol is used more often (Kairouz et al. 2002), and consumption is higher (Demers et al. 2002). However, these studies were conducted among university students and were limited to alcohol use only.

With respect to group size, the relationship between another type of deviant behavior (i.e. offending) and the number of peers has been investigated (Bernasco et al. 2013; Weerman et al. 2015). These studies support the importance of group size given that the presence of multiple peers, only or more strongly, affected offending. Because substance use is viewed as a more innocent form of deviant behavior (Augustyn and McGloin 2013), it can be argued the presence of only one peer could already be sufficient to provoke substance use, and that the presence of multiple peers further increases the probability. Thus, we hypothesize that adolescents are more likely to use substances in the presence of peers than in the absence of peers $(\mathrm{H} 2 \mathrm{a})$, and that with increasing group size they are more likely to use substances $(\mathrm{H} 2 \mathrm{~b})$.

\section{Absence of Authority Figures}

Supervision by authority figures is a situational form of social control. Here, social control does not refer to an individual's bond to conventional society (Hirschi 1969), but to the use of social means to manipulate the behavior of others (Gibbs 1981). Authority figures are defined as individuals whose role in a situation accompanies a responsibility for trying to exert social control in response to deviant behavior (Osgood et al. 1996). This responsibility can arise from the role in the setting (e.g. police officer), or from the personal bond with the individual (e.g. parents). The implicit assumption here is that authority figures do not approve substance use. Thus, if authority figures are not present, social control is limited, resulting in a decreased risk of receiving disapproval or getting caught and being sanctioned for substance use. Again, these arguments are in line with a rational perspective on decision-making (Cornish and Clarke 1986), as the presence of authority figures implies the risk of sanctions (e.g., fines, home arrest, school expulsion) or other negative or painful responses (rejection, disapproval) of authority figures when they observe deviant behavior.

Previous studies on the influence of authority figures are limited and focused on family authority figures. The few studies that explicitly measured the absence of authority figures found that adolescents who spent more time without adult supervision used more alcohol and drugs (Augustyn and McGloin 2013; Flannery et al. 1999). Other studies looked at more indirect measures of presence of family authority figures and found a negative association between substance use, and either time spent with family (Barnes et al. 2007; Vazsonyi et al. 2002) or parental social control (Anderson 2003; Meldrum and Clark 2015). In 
sum, we expect that adolescents are more likely to use substances in the absence of authority figures than in their presence $(\mathrm{H} 3)$.

\section{Interaction of Situational Elements?}

The previous sections have discussed the effects of three elements on deviance separately. An additional question is whether and how the effects of the three elements are interrelated. Do combinations of situational elements generate less or more risk for substance use than the sum of their separate effects? In other words, do the elements of unstructured socializing interact? The routine activity theory of deviant behavior (Osgood et al. 1996) defines unstructured socializing as unstructured activity with peers and without authority figures present. In our reading, the exposition of the theory by Osgood et al. (1996) remains ambiguous as to whether the three situational elements (presence of peers, absence of authority figures, and unstructured activities) are proposed to interact, such that either the presence of each factor increases the effects of the other two factors, or even that the joint presence of all three conditions is required for deviant behavior to take place. On the one hand, the interaction hypothesis appears to be implied by the definition of unstructured socializing as the combination of unstructured activity in the presence of peers and without authority figures present, and by the corresponding measurement of the concept by items from the questionnaire of the Monitoring the Future panel study. On the other hand, the separate discussion of each of the three situational elements as independent factors suggest that the interaction may not be central to the theory. For example, the authors note "This is not to say that the presence of peers is a necessary condition for deviant behavior (...). We simply claim that, other things being equal, spending more time with peers exposes an individual to more situational inducements to deviance, and this leads to higher rates of deviance." (p. 639). Whether or not the interaction should be considered a key proposition of the theory, it is an interesting and practically relevant hypothesis to test empirically.

No previous literature exists that explicitly addresses this issue with respect to substance use, but two studies did investigate the interaction hypothesis with respect to offending, another type of deviant behavior. Both studies used independent measures of presence of peers, absence of authority figures and unstructured activity, and could therefore statistically test the interaction. Weerman et al. (2015) found that spending more time with peers is not related to offending if none of the other conditions are met (e.g. in school when activities are structured and supervised by teachers), whereas time spent with peers is related to offending when it takes place in combination with unstructured activities in the absence of authority figures. Their results are in line with the routine activity theory as used by Osgood et al. (1996) and suggest some interaction, but the argument that all three conditions are necessary for deviant behavior to take place was not supported by the study of Weerman et al. (2015). Bernasco et al. (2013) examined in what situations offending is most likely to occur. Distinguishing the same three elements of unstructured socializing, ${ }^{1}$ they found overall support for the routine activity of deviant behavior. However, the effects of the situational elements were found to merely accumulate, but not interact. The limited available evidence on offending thus suggest that the elements of unstructured socializing do have independent effects on deviant behavior, but need not all be present simultaneously

\footnotetext{
1 The model also included a variable indicating the type of location (public, semi-public or private space) where time was spent.
} 
to provoke it. However, given the centrality of the concept of unstructured socializing (which implies the simultaneous presence of the three situational elements) in the routine activity theory of deviant behavior, and taking into account the lack of empirical evidence on substance use, it seems justified to hypothesize that the three elements interact, so that the effect of each of the three situational elements is strengthened by the presence of the other situational elements (H4).

\section{Data and Method}

\section{Data}

Data from the Study of Peers, Activities, and Neighborhoods (SPAN) is used, conducted by the Netherlands Institute for the Study of Crime and Law Enforcement (NSCR). This study was conducted to gain insight in the activities, and delinquent behavior, of adolescents.

A random sample of 40 secondary schools was drawn in the city of The Hague and its suburbs, of which ten schools agreed to participate. The main reason for school refusal was the perceived overload of research participation requests: Many research projects in The Netherlands recruit study participants through schools, and to curb the burden on pupils and school personnel, schools tend to limit collaboration to a few studies annually. The school response rates did not display any bias with respect to school size or with respect to geographical location, but the sample was not fully representative with respect to school type. $^{2}$

The data was collected in two waves. For the sample of the first wave (2008/2009), all first graders (age 12/13) and fourth graders (age 15/16) of the participating schools were asked to take part in the study. Movie vouchers were used as an incentive and the pupils could participate during school hours. A letter was sent to the parents to inform them, and to provide the opportunity to refuse participation (passive consent). The response rate was $93 \%$. $^{3}$ Two years later $(2010 / 2011)$ the second wave of the study was conducted. All respondents of the first wave were asked to participate again. The data collection resulted in 868 adolescents in the first wave and 616 adolescents in the second wave. The response rate in the second wave was thus $71 \%$. The main reason provided for pupil non-response in the second wave was lack of time or unwillingness to participate (65\% of the non-responders).

Non-responders were generally older and had reported more involvement in unstructured socializing and theft. They were slightly more tolerant toward substance use and offending, reported more delinquency of their friends and less parental monitoring. They did not differ significantly on self-reported violence, vandalism or general delinquency (Hoeben 2016).

\footnotetext{
${ }^{2}$ The Netherlands has a free public school system characterized by multiple-track secondary education. Our sample contained an over representation of schools with 4-year tracks (vocational training) and of schools with 6-year tracks (pre-university), and an underrepresentation of the 5-year track (middle category).

${ }^{3}$ The main reasons for individual nonresponse were a too high workload in school, parents withdrawing their children from the study, not showing up at the appointment, moving to another school, and illness at the day of the interview. These nonresponse groups form only a small percentage of the target group (varying between 0.3 and $3.0 \%$ ).
} 
We should acknowledge the possibility that the strength of the relation between situational elements and substance use varies between participants and non-responders. For example, if non-responders would be more susceptible to peer pressures, our findings would somewhat underestimate the relation between substance use and presence of peers. However, this potential bias is minimized by the fact that the differences are relatively minor, the response in the first wave was as high as 93\%, and our analytical strategy (fixedeffects panel regression) effectively removes any biases due to stable between-person confounders. Furthermore, we see no particular reason, to assume that situational effects operated differently for non-responders than for participants in the second wave.

\section{Research Instrument}

We used a space-time budget (STB) interview to collect hour-to-hour information about four recent days, resulting in 96 observations for every adolescent. The instrument is a translated and slightly adjusted version of the original instrument developed by Wikström et al. (2010).

The participants were asked retrospectively about the most recent Friday and Saturday (further referred to as weekend days), and the two most recent week days. The interview was conducted individually and face-to-face with the respondents. This took about $1 \mathrm{~h}$ and was done by trained research assistants. Attempts have been made to minimize social desirable answering: the respondents had the possibility to provide nonverbal answers (e.g. nodding) and all interviewers were college students or recent graduates, to make sure the interviewer-respondent social distance was not too big and neither too small. The interviewers helped the respondents in chronologically reporting the events and activities they performed during the day, and when necessary probed for information.

Detailed information was reported about the main activity, the function of the place, the geographic location, and the persons present. Respondents provided the answers in their own words and these were coded by the interviewers using lists of codes (for code lists see Wikstrom and Butterworth 2006; Wikstrom et al. 2012). In addition, respondents were asked specifically whether and during which hour they used alcohol or drugs. In support of the validity of the STB instrument, Hoeben et al. (2014) demonstrate that measures on substance use in the STB instrument correlate strongly to items of the self-report questionnaire for the same participants, which ask for substance use more generally (for an extensive review of the STB instrument, see Hoeben et al. 2014).

In the present study, we focus on the age group of 14-16 year old adolescents, because this is the period in which deviant behavior generally peaks (Loeber and Farrington 2014). All observations of the oldest age cohort of the first wave (mainly age 15/16) and the youngest age cohort of the second wave (age 14/15) are selected (775 individuals).

To explain within-individual differences in substance use across situations we apply a fixed-effects regression model for panel data. This model makes few assumptions, and in estimating effects only compares outcomes from multiple observations from different situations of the same individual. This implies that in explaining substance use, we only use data on the 229 individuals who used substances at least once during the 4 days that are included ( $N=21,984$ observed hours). The others did not report using substances at any time during the 4 days covered, and hence do not vary across situations. In line with other articles (Averdijk and Bernasco 2015; Bernasco et al. 2013), we removed sleeping hours 
from the analysis because substance use is not possible during sleep. ${ }^{4}$ There are no missing values on the dependent variable (substance use) and the missing values on the independent variables are negligible (less than $0.1 \%$ ). The missing observations were removed from the analysis using listwise deletion. The total $N=14,665 \mathrm{~h}$ on 229 participants during 4 days, an average of $16 \mathrm{~h}$ per day (excluding $8 \mathrm{~h}$ of sleep).

\section{Measures}

The unit of analysis is a person-hour, and all variables apply to the person-hour level, not to the person.

\section{Dependent Variable}

To measure substance use, the question "Have you used alcohol or drugs during this day?" was asked at the end of the coding of each day. If respondents reported substance use, details about when and what kind of substances were recorded. Up to three different types of substances could be reported per hour: (1) alcohol (e.g. beer, wine), (2) soft drugs (e.g. weed, hash), and (3) hard drugs (e.g. XTC, speed). Alcohol is by far the most reported substance $(N=961)$, followed by soft drugs $(N=247)$, and hard drugs $(N=4)$. Note that substances can be used in combination and as a result there is overlap between the categories. Respondents reported to use any substance in $1044 \mathrm{~h}$. Alcohol was used exclusively in $794 \mathrm{~h}(76.1 \%)$, other drugs (soft drugs or hard drugs) were used exclusively in $165 \mathrm{~h}$ $(15.8 \%)$, and the simultaneous use of both alcohol and other drugs in the remaining $85 \mathrm{~h}$ $(8.1 \%)$.

In the main analysis of this study, we combine these items into one dummy variable which indicates whether respondents in a given hour reported "no substance use" (0) or "any substance use" (1).

The routine activity theory of deviant behavior is a general theory of all types of deviant behavior. Although substance use may be a viewed as a homogeneous behavioral category, there are cultural and legal differences between the use of alcohol and the use of other drugs, both in terms of availability (alcohol is widely available in many cultures and countries but other drugs much less so) and criminalization (soft drugs and hard drugs are strictly prohibited in many jurisdictions, but alcohol much less so). As a supplementary assessment of the robustness of the theory to variations in substance use, we performed additional analyses separately for use of alcohol and for use of other drugs. As the theory does not distinguish between alcohol and other substance, its support would be broadened if it were demonstrated that the theory equally applies to both types of substance use.

\section{Independent Variables}

First, the dataset contains information about the type of activity during each hour. The respondents reported 127 different types of activities. We recoded these activities into a dummy variable with two values: "structured activities" (0) and "unstructured activities"

\footnotetext{
4 An issue is that respondents were asked about the main activity they performed during each hour. Respondents might have used substances when they were awake in the same hour they went to sleep, but if sleeping was their main activity that hour, that is what they reported. This only applied to 2 cases.
} 
(1). In accordance with the study of Bernasco et al. (2013), we categorize unstructured activities as activities in which the timeframe is undecided, without a fixed end point, and in which socializing is the main activity. This means that only those activities that are clearly unstructured (e.g. 'hanging around', 'going to a birthday party') are coded as such, and activities that can be considered both structured and unstructured are coded as structured activities (examples are 'watching a film' and 'bowling'). Clearly structured activities include items such as 'school classes and lectures', and 'football'. To check the robustness of the results, we also conducted all our analyses using a broader definition of unstructured activities that includes the activities that can be regarded both structured and unstructured (see Table 4 in the Appendix).

Second, the presence of peers was measured in the SPAN data, including gender and number of peers present. Examples of the items are ' 1 male peer' and ' 2 or more female peers'. We recoded this variable to "no peers present" (0), "1 peer present" (1), and "more than 1 peer present" (2). Peers include friends, siblings (younger than 18 years of age), and partners.

Finally, the concept absence of authority figures was operationalized using two variables in the dataset. The first variable measures what type of family (e.g. parents, brother) was present, and the second variable measures what type of others (e.g. teacher, employer) were present. All adult family members are considered family authority figures and all adult people who are personally known to the respondent are considered other authority figures. In line with previous literature (Hoeben and Weerman 2014; Weerman et al. 2015), we use a broad definition of authority figures that includes both family authority figures and other authority figures. We thus coded the presence of authority figures with two values: "family or other authority figure present" (0) and "family or other authority figure absent" (1).

\section{Control Variables}

Drinking alcohol and using drugs is expected to be more likely to occur on particular days and hours. It has been shown that substances are used more often on weekend days than on week days (e.g. Demers 1997; Kairouz et al. 2002). With respect to hours, we expect substances are mostly used in the evening and night hours. To account for these temporal variations, we included as controls two dummy variables, indicating whether the hour was during a weekend day (Friday 6p.m.-Sunday 6a.m.) and in the evening or night time (6p.m.-6a.m.). Note that these variables cannot provide substantive explanations of substance use, but are likely related to unmeasured time-varying variables (e.g. physical state of an individual). By inclusion of the temporal controls, we can partly correct for this possible bias. The issue will be explained below in further detail.

\section{Statistical Models}

In order to explain why a person uses substances in one situation but not in the other, a within-individual research design involving repeated measures of the same individual across different situations is optimal. As experimental designs are ethically and practically not feasible, a fixed-effects panel analysis of the space-time budget data is the second best option (Brüderl and Ludwig 2015; Halaby 2004). In this type of model the estimates are based only on comparisons between repeated observations of the same individual, and they 
are therefore not confounded by stable measured or unmeasured individual characteristics (e.g. age, gender, self-control).

In this study, there are 96 repeated observations (every hour for 4 days) for each individual. Fixed effects models can only include individuals that vary on the dependent variable, and thus the analyses are restricted to the 229 individuals who used substances at least once during the 4 days.

As a check on the robustness of our findings, we also calculated estimates using random effects models. These models make stronger assumptions on the data than fixed effects models do, and provide less safeguards against confounding, but are based on information on all 775 individuals in the sample, including those who did not use substance during the 4 days. Random-effect estimators are more efficient than fixed-effect estimators because fixed effect-estimators are only based on within-person variation (here: across observed hours of the same individual), whereas random-effects estimators are based both on withinperson and between-person variation. ${ }^{5}$

Because substance is not possible while sleeping, only awake hours are included in the analyses. With an average of $8 \mathrm{~h}$ sleep per day, this results in an average of 64 observations per person. For the dependent variable, the number of hours in which substances are used is $1047(7.1 \%)$ of 14,686 recorded awake hours.

The estimated parameters are presented as coefficients $(b)$ in the linear equation of the logit, and also as odds ratios $\left(e^{b}\right)$. Odds ratios represent the multiplicative effect of a unit increase of the independent variable on the odds of using substances. In the case of a binary independent variable (e.g. structured vs. unstructured activity), it represents the difference in the odds between both categories. A negative effect of an independent variable on the odds of substance use is indicated by a value between 0 and 1. Odds ratios larger than 1 indicate a positive effect as the odds of using substances increases. In this study, all hypotheses are formulated in terms of the increasing risk of substance use, and thus odds ratios are hypothesized to be larger than 1 for each of the independent variables.

\section{Results}

\section{Descriptive Results}

Descriptive statistics on substance use, unstructured activities, presence of peers, and absence of authority figures are presented in Table 1, where person-hours are the units of analysis. Table 1 shows, for each category of the situational elements (in the rows), the numbers of hours that substances were used (column A), the numbers and percentages of hours spent in the category (columns B and C, and columns E and F), and the percentage of hours that substances are used per category (columns D and G). The statistics are shown for substance users only (A, B, C and D) as well as for the full sample (E, F and G).

Generally, substance users spend similar percentages of time in activity categories as the full sample (columns $\mathrm{C}$ and F), although substance users spend consistently somewhat more time in the categories that represent unstructured socializing (25 against $19 \%$ for

\footnotetext{
5 The random effects panel data model is a multilevel model restricted to two hierarchical levels. In our analysis, these levels are hours (level 1) that are nested in individuals (level 2). The independent variables in the random effects models reported in the Supplementary Information are centered on their grand means across hours and individuals.
} 


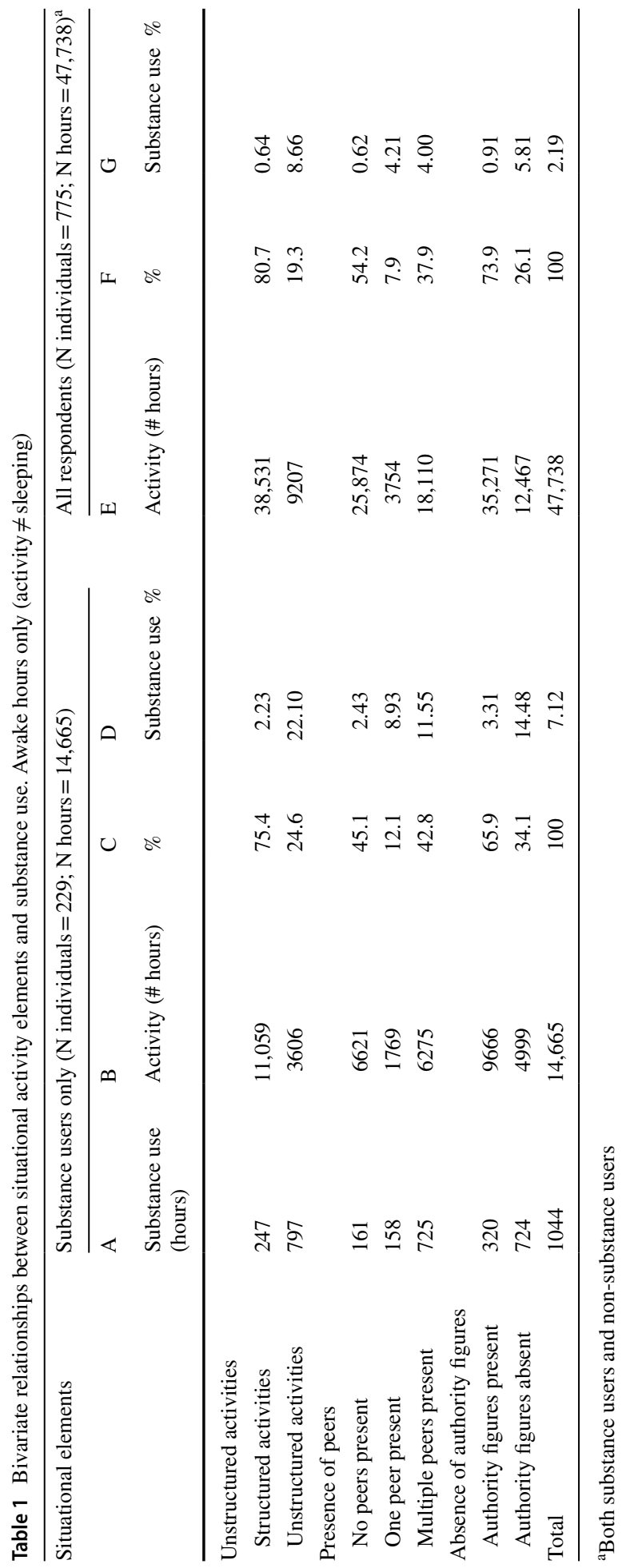


unstructured activities, 55 against $46 \%$ for time with peers and 34 against $26 \%$ for time without authority figures).

Table 1 further demonstrates that the percentage of time spent using substances varies considerably across situational elements (columns D and G). Here, we discuss only the subsample of substance users (column D). In line with the first hypothesis, adolescents used substances in $22 \%$ of the time in unstructured activities, but only in $2 \%$ of the time spent in structured activities. In support of $\mathrm{H} 2 \mathrm{a}$ and $\mathrm{H} 2 \mathrm{~b}$, of the hours spent without peers, with a single peer, and with multiple peers, 2, 9 and 12\%, respectively, involved substance use. Finally, $3 \%$ of time spent with authority figures involved substance use, against $14 \%$ of the time without authority figures (H3). Though not conclusive, the descriptive results are in line with the hypothesized relations.

\section{Correlations Between the Situational Elements and Substance Use}

For the subsample of 229 substance users, correlation coefficients were calculated amongst substance use and the three situational elements. Again, person-hours are the units of analysis. The correlation coefficients show that all three situational elements are positively related to substance use. Substance use is most strongly related to involvement in unstructured activities $\left(r_{\mathrm{t}}=0.659, p<0.001\right)$. Substance use is also more likely in the absence of authority figures $\left(r_{\mathrm{t}}=0.465, p<0.001\right)$ and in the presence of peers $\left(r_{\mathrm{t}}=0.426, p<0.001\right)$. Furthermore, all correlations between the situational elements are positive. Unstructured activities happen more often in absence of authority figures $\left(r_{\mathrm{t}}=0.407, p<0.001\right)$ and to a lesser extent also in presence of peers $\left(r_{\mathrm{t}}=0.295, p<0.001\right)$. Finally, the presence of peers is also more likely to go together with the absence of authority figures $\left(r_{\mathrm{t}}=0.156\right.$, $p<0.001)$.

\section{Fixed Effects Logistic Regression Models}

Above it was hypothesized that all three situational elements-unstructured activity, peer presence and authority figure absence-uniquely contribute to substance use $(\mathrm{H} 1, \mathrm{H} 2 \mathrm{a}$, $\mathrm{H} 3$ ). In addition, we hypothesized that the presence of multiple peers would more likely provoke substance use than the presence of a single peer $(\mathrm{H} 2 \mathrm{~b})$. Furthermore, we expected the effects of the situational elements interact by strengthening each other (H4). These expectations were tested using fixed effects logistic regression models. The results are shown in Table 2. Although according to accepted standards in inferential statistics directional hypotheses allow for one-sided significance tests, we conform to the contemporary standard in most academic journals and conduct two-sided tests on all variables, including key variables and control variables. To avoid the arbitrariness of specific $p$ value thresholds and allow for the calculation of one-sided significance levels, we report exact $p$ values.

Model FE1 includes the main effects of the three situational elements simultaneously. The results confirm hypothesis 1 that adolescents are more likely to use substances in unstructured activities than structured activities (odds ratio 5.237). The odds of substance use are 3.818 times larger when one or more peers are present compared to when no peers are present, confirming hypothesis $2 \mathrm{a}$. Also, hypothesis 3 is confirmed, as adolescents are more likely to use substances in the absence of authority figures than in their presence (odds ratio 2.426). With respect to the relative importance of the elements, the effect of unstructured activities (odds ratio 5.237) is larger than the effect of the presence of peers (odds ratio 3.818), which in turn is larger than the effect of the absence of authority figures 


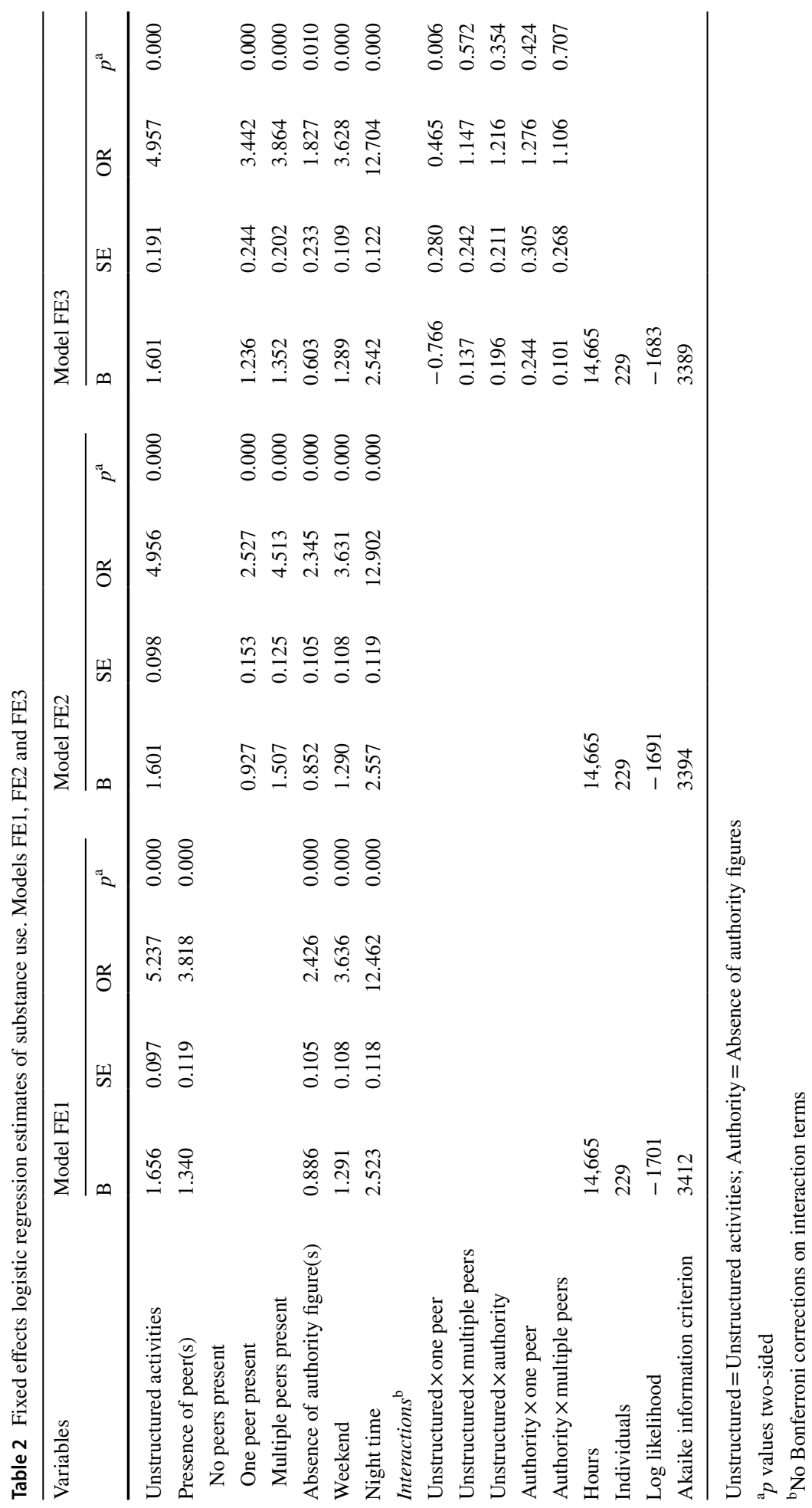


(odds ratio 2.426). ${ }^{6}$ Thus, unstructured activities seem to be most important, followed by the presence of peers, and then the absence of authority figures.

In Model FE2 the distinction between one and multiple peers is considered. The results show that the presence of two or more peers (odds ratio 4.513) has a greater positive effect than the presence of only one peer (odds ratio 2.527), and this difference is statistically significant $\left(\chi^{2}(1)=18.85, p<0.001\right)$. This confirms that if peer group size increases, adolescents are more likely to use substances (hypothesis $2 b$ ). The effects of the two other situational elements do not substantially change. Comparison of the model fit based on the Akaike information criterion (AIC) shows Model FE2 is preferred over Model FE1 as this model has a lower AIC.

In Model FE3, all two-way interaction terms between the situational elements are included. The results show no interaction effects between the absence of authority figures and either unstructured activities or the presence of peers. ${ }^{7}$ With respect to unstructured activities and the presence of one peer, a negative interaction effect is found where a positive one was expected. This means that during structured activities, substance is equally likely in the presence of a single peer as in the presence of multiple peers (odds of 3.442 and 3.864 respectively), but that in unstructured activities, substance use is more likely in the presence of multiple peers than in the presence of a single peer (odds of 19.154 and 7.934 respectively). ${ }^{8}$ The fact that the odds of substance use do not increase as much for unstructured activities when one peer is present (compared to the increase in odds for multiple peers) seems to be driven by a specific unstructured activity, namely the item 'talking face-to-face'. In over $60 \%$ of all situations in which one peer was present and no substances were used $(N=490)$ adolescents were talking face-to-face, whereas the other $40 \%$ of the situations was spend in 12 different types of activities. Therefore, a plausible explanation for the negative interaction effect is that substance use is unusual to occur in a situation in which adolescents are talking face-to-face with one friend specifically rather than that it is less likely to occur when one peer is present during unstructured activities in general. ${ }^{9}$ To conclude, no support is found that the effect of one situational element is strengthened by presence of the other situational elements. This means hypothesis 4 is rejected. ${ }^{10}$

\footnotetext{
${ }^{6}$ The differences between the effect of unstructured activities and both the effect of presence of peers and absence of authority, are statistically significant (respectively $\chi^{2}(1)=3.71, p<0.05 ; \chi^{2}(1)=26.89$, $p<0.001)$. The effect of the presence of peers is significantly larger than the effect of the absence of authority figures $\left(\chi^{2}(1)=6.49, p<0.01\right)$.

${ }^{7}$ As a first step, Model 3 was estimated including the three-way interaction term but this was not significant. Table 2 shows the model estimations only including the two-way interactions. Because the five interaction terms jointly test a single hypothesis (H4), Bonferroni corrections should be applied to the corresponding reported $p$ values. These (unreported) corrections inflate the $p$ values, further reducing their statistical significance.

${ }^{8}$ The first odds ratio is calculated by multiplying the main effects $4.957 \times 3.864=19.154$, the second by multiplying the main effects and the interaction effect $4.957 \times 3.442 \times 0.465=7.934$.

${ }^{9}$ To check the robustness of the results, a broader definition of unstructured activities was considered that includes the activities that can be regarded both structured and unstructured (see Table 4 in the Appendix). The negative interaction effect between unstructured activities and the presence of one peer was not observed here. This finding supports the proposed explanation as under this broad definition of unstructured activities this activity forms a smaller percentage (28\%) of all unstructured activities.

${ }^{10}$ In addition to the three models shown in Table 2, a fourth model was estimated. In model FE4, the interaction effects are tested using the dichotomous variable of the presence of peers, thus following the same operationalization of this variable that was used in Model FE1. No interaction effects were found. Based on the value of the AIC, Model FE1 is preferred of Model FE4. See Appendix, Table 5 for the full results of model FE4.
} 
Table 3 Fixed effect logistic regression estimates of substance (alcohol vs. other drugs). Model FE1

\begin{tabular}{|c|c|c|c|c|c|c|c|c|}
\hline \multirow[t]{2}{*}{ Variables } & \multicolumn{4}{|c|}{ Model FE1 alcohol } & \multicolumn{4}{|c|}{ Model FE1 other drugs } \\
\hline & B & SE & OR & $p^{\mathrm{a}}$ & B & SE & OR & $p^{\mathrm{a}}$ \\
\hline Unstructured activities & 1.813 & 0.111 & 6.126 & 0.000 & 0.840 & 0.185 & 2.317 & 0.000 \\
\hline Presence of peer(s) & 1.596 & 0.141 & 4.932 & 0.000 & 1.044 & 0.215 & 2.839 & 0.000 \\
\hline Absence of authority figure(s) & 0.627 & 0.119 & 1.873 & 0.000 & 1.596 & 0.206 & 4.935 & 0.000 \\
\hline Weekend & 1.824 & 0.139 & 6.195 & 0.000 & 0.085 & 0.165 & 1.089 & 0.606 \\
\hline Night time & 3.319 & 0.174 & 27.619 & 0.000 & 1.063 & 0.172 & 2.894 & 0.000 \\
\hline Hours & 13,822 & & & & 3631 & & & \\
\hline Individuals & 216 & & & & 57 & & & \\
\hline Log likelihood & -1331 & & & & -534 & & & \\
\hline AIC & 2672 & & & & 1079 & & & \\
\hline
\end{tabular}

${ }^{\mathrm{a}} p$ values two-sided

In Table 3, using the same set of independent variables as in model FE1 of Table 2, and motivated by the cultural and legal differences attached to both categories of substances, separate estimates are presented for use of alcohol and use of other drugs. The results support the routine activity theory of deviant behavior as they indicate that its propositions are valid for both types of substance use: The three key situational elements (presence of peers, absence of authority figures and unstructured activity) are positively and significantly related both to the use of alcohol and to the use of other drugs.

A closer inspection of differences between the two models suggests that the presence of peers and the involvement in unstructured activities are related more strongly to alcohol use than to drug use, whereas the absence of authority figures is more strongly related to other drug use than to alcohol use.

Table 6 in the Appendix repeats the fixed effect estimates of Model FE1, together with two sets of estimates from random effects models, the first using data on the 229 substance users only and the second using data on the full sample of 775 individuals. The random effects estimates are in line with those of the fixed effects model, and support the substantive conclusions made. We provide online Supplementary Information presenting similar tables for Model FE2 and model FE3. Although random effects models would allow us to investigate effects of stable individual characteristics (e.g. gender) on substance use or to investigate between-individual differences in the effects of situational elements on substance use (e.g. whether peer presence affects girls more than boys), these questions are beyond the scope of the theory that is being tested, and were therefore not further explored. The random effects estimators are thus only used as a robustness check on the fixed effects estimators.

These conclusions are confirmed and strengthened by the results of additional models (included as Table S3 and Table S4 in the Supplementary Information) in which the other two models (Model FE2 and Model FE3) are separately estimated for alcohol and for other drugs. With the exception of the relation between the presence of peers (coded as no peers 
vs. one peer versus multiple peers present) and other drug use, all other situational elements are positively and significantly related to both alcohol use and other drug use. The differences in the strengths of the relations between the situational elements between alcohol use and other drug use are also confirmed.

\section{Discussion}

Individual differences in adolescents' substance use have extensively been studied, but less is known about the situations in which they use, or refrain from using, alcohol and drugs. The present study used unique space-time budget data to explain not who are the most likely substance users, but what are the most likely types of situations in which they use substances. Informed by the routine activity theory of deviance (Osgood et al. 1996), we studied the effects of three situational elements on substance use: unstructured activities, presence of peers, and absence of authority figures. Space-time budget data were collected on 868 adolescents (775 used in the analysis). They provide four full days of hour-to-hour measures of where, when, with whom, and what they were doing. For the 229 adolescents who used substances during at least $1 \mathrm{~h}$ in these 4 days, we use a fixed effects logistic regression analysis to compare the situational elements of the hours in which they used substances, with those of the hours in which they did not. In doing so, we test what situations provoke substance use, while controlling for stable individual differences (i.e., by using a within-subjects design).

Our findings are mostly in line with the routine activity theory of deviance, but they also suggest a potential correction. They confirm that unstructured activities, presence of peers, and absence of authority figures provoke substance use among adolescents. They also confirm that whereas the presence of one peer is sufficient to provoke substance use, the presence of multiple peers makes substance even more likely. However, we did not find support for the idea that the effects of situational elements interact, i.e. that they are either strengthened or weakened by each other, a hypothesis that seems to be implied by the theory. In fact, all three situational elements seem to encourage substance use independently of the other situational elements. In the routine activity theory of deviant behavior, the concept of 'unstructured socializing' includes the convergence in time and place of unstructured activity, presence of peers and absence of authority figures. Strictly speaking, this implies that a situation should not provoke deviant behavior if at least one of the three elements is not present in a situation (i.e., if the activity is structured, if no peers are present, or if authority figures are present). In other words, the theory would predict that the situational elements interact, whereas our findings suggest that they merely accumulate in an additive way. A similar conclusion was drawn by two studies that tested the theory by studying offending behavior rather than substance use (Bernasco et al. 2013; Weerman et al. 2015).

The routine activity theory of deviant behavior applies to all deviance and should thus not only successfully predict substance use, but also other types of delinquent and criminal behavior. Therefore, comparing our findings to the results of prior work on situational correlates of offending is relevant. Here, we compare our findings to a study that used the same space-time budget data as we did to investigate correlates of criminal offending, including 
assaults, vandalism and theft but not substance use (Bernasco et al. 2013). Although Bernasco and colleagues used a full pooled sample across both waves of the panel (whereas we used an age-restricted subsample) and although all their models included a variable indicating whether the time was spent in public space (as opposed to semi-public or private space), their findings on offending are in line with our findings on substance use, as they found support for the three situational elements (presence of peers, absence of authority figures, and unstructured activity) but no evidence for the elements to interact. Note that Bernasco and colleagues estimated models (2, 3 and 5) that included use of alcohol, use of cannabis, and weapon carrying as additional situational elements (i.e., as independent variables), and concluded that alcohol use was strongly and statistically significantly related to offending. Although they not perform a mediation analysis (Baron and Kenny 1986) to assess whether alcohol use mediates the relation between the three situational elements and offending, their results do not suggest that this is the case: the inclusion of alcohol use hardly affected the estimates of presence of peers, absence of authority figures and unstructured activity.

By dissecting unstructured activity, peer presence and authority absence at the level of situations, the present study offers detailed information about the three situational elements and their effects on substance use. With respect to the relative importance of the situational elements, unstructured activities seem to matter most. Substance use is most likely to occur during clearly unstructured activities that carry no agenda and pre-defined goals. Even when the threshold for being an 'unstructured' activity is lowered (e.g. by including 'shopping for fun' as an unstructured activity), substance use is still more likely to occur during unstructured than during structured activities. Peers have the second most important influence on substance use. In accordance with the mechanisms of peer influence as theorized by Warr (2002), we find that substance use is more likely to occur in presence of multiple peers. The importance of group size was shown for other forms of deviant behavior (i.e. offending), but substance use appears to be unique in the sense that the presence of only one peer already provokes this behavior while it does not for offending (Bernasco et al. 2013). This finding suggests that substance use might be considered a more innocent form of deviant behavior, as proposed by Augustyn and McGloin (2013). Finally, the odds of using substances are higher when authority figures are absent than when they are present. Supervision could be either by family authority figures or other authority figures (e.g. teachers). Whereas parents may differ in their approval of alcohol and drug use (Gilligan and Kypri 2012; Kypri et al. 2007), we expect most teachers disapprove of substance use, as their professional roles and standards probably overrule any positive personal attitudes they might have towards adolescent substance use.

\section{Policy Implications}

Adolescent substance use is associated with negative consequences in various life domains, and therefore challenges parents, teachers, other supervisors and policy makers to find ways to discourage the use of alcohol and drugs by adolescents. Although there are certainly many individual differences that distinguish adolescents who use substances from those who abstain, our findings highlight the possibility of changing 
situations rather than individuals. In general, it seems easier to change situations than to change individuals. Policies or measures that increase the amount of structure in adolescent activities, decrease the convergence of peers and increase supervision by authority figures, are likely to situationally discourage substance use. However, joint activities with peers should probably not be actively discouraged, because they have many positive effects, for example on well-being (Raja et al. 1992). Therefore, it may be advisable that interventions offer structured activities and provide supervision by authority figures, rather than limit the co-presence of peers. The findings suggest effectiveness of intervention programs that use promotion of sports, an example of a structured activity, to reduce substance use (e.g. Werch et al. 2003, 2005). Furthermore, policies that focus on adult supervision are recommended, for example in terms of parental monitoring (e.g. Janssen et al. 2014). As not all parents might disapprove alcohol and/or drugs use of their children, these policies are best combined with information programs about the negative consequences that are associated with substance use at an early age (e.g. Werch et al. 2003).

\section{Limitations}

Like all studies, the present one has some limitations that need to be addressed. First, data collection is limited to 4 days per respondent and it is assumed these days are representative for a longer period of time. There is a possibility that the results are influenced by the timing of the data collection that took place between November and March. For example, during the winter adolescents might spend less time outdoors, typically in absence of (family) authority figures, than during the summer. To get more insight in this, it would be beneficial to replicate the study in a different season.

Second, the sample of Dutch adolescents that was used is not random and representative. In contrast to the individual-level response rate of $93 \%$, only $25 \%$ (10 out of 40 ) of the schools in the sample frame agreed to participate in the study. As a result, lower educated adolescents and adolescents with a nonnative ethnic background are overrepresented in the data (Hoeben 2016). Although there are no specific reasons why substance use in these groups would be different from substance use in other groups, the non-random and unrepresentative nature of the sample of students might mean that the adolescents in our sample react differently to situations than a representative sample of the larger population. To prevent potential bias, future studies using stratified sampling designs should strive for acceptable participation rates at all stratification levels, not only at the level of the individual [see van der Gaag et al. (2019) for strategies to improve participation rates of schools].

Third, the measurement of group size in this study is restricted to a distinction between one peer and two or more peers. A continuous measure might enable a more accurate test of the effect of group size on substance use. 
Fourth, respondents might be consciously or subconsciously biased when reporting the times and places of substance use. For example, the time that an adolescent drank alcohol with friends, involved in unstructured activities away from parents, might be easier to remember than the time he or she drank a beer alone at home. The innovative STB instrument that was used attempts to minimize these problems by using a relatively short time frame (1 week) and by asking specifically and explicitly about substance use for every day included. In this regard, previous studies also highlight the benefits of time use data over survey data (e.g. Schulz and Grunow 2012).

Finally, like all non-experimental empirical research, our empirical design limits the ability to make causal inferences about the situational correlates of substance use. Although fixed effect estimates help us to reduce the risk of confounding by unobserved stable individual differences, they do not necessarily represent causal relations. Bjerk (2009) warns for the potential bias created by 'dynamic selection', which occurs if individuals self-select on the independent variables. In the case of adolescent substance use, for example, the absence of authority figures and the presence of peers may not directly cause substance use. Rather, some adolescents may avoid the presence of authority figures and seek each other's company in order to create the opportunity and be able to enjoy substance use.

\section{Future Research}

The limitations of this study and other considerations suggest several recommendations for future research. This research was carried out in the Netherlands, and it would be valuable to replicate it in countries with different laws regarding the use of alcohol, cannabis and other drugs, and with different policies that regulate their availability of alcohol and drugs. Alcohol use was permitted from the age of 16 years in the Netherlands at the time of the study. With respect to soft drugs (cannabis), for which the same age limit applies as for alcohol, a policy of tolerance exists and hard drugs is illegal. By January 1, 2014, the age limit for both alcohol and soft drugs has been increased to 18 years. For example, in the United States the age limit is considerably higher (21 years) and therefore it is perhaps more difficult for adolescents to obtain alcohol and drugs. Empirical evidence from cross-national comparative research suggests that for alcohol use, the stricter rules in the USA are effective in reducing adolescent alcohol use as compared to Canada and The Netherlands, but that this effect does not apply to cannabis use (Simons-Morton et al. 2010). Another cross-national comparative study showed that cross-national variations in rules and policies do not affect the age of onset of use of alcohol, cannabis and other drugs (Vega et al. 2002). Future research might add to these insights by uncovering cross-national differences in the role of situational elements in adolescent substance use.

Clearly the focus of the current study was on the influence of situational effects on substance use, and individual differences were filtered out by our analytical strategy 
of using a fixed-effects panel regression model. Studying individual differences was beyond the scope of this article. However, vulnerability for situational effects might differ between individuals (e.g. by gender, education, and self-control). Previous research has shown person-environment interactions are important for offending. For example, Svensson and Pauwels (2010) found that individuals with higher offending propensities were more vulnerable for environmental inducements. This may also be the case for substance use. Future research could benefit from incorporating personenvironment interactions (see for more details Wikström et al. 2018) to identify for whom the situational influences on substance use matter most, and may apply random effects panel models to estimate them (Beier 2018).

Although we see the situational measurement of the presence of peers, the absence of authority figures and unstructured activities as an important step towards understanding adolescent substance use, these measures obviously do not tap all relevant situational variation. Future research might focus on an improved specification of the measure of peer presence, as the literature on peer effects (Beier 2018; Brechwald and Prinstein 2011; Hoeben et al. 2016; Thorlindsson and Bernburg 2006) clearly suggests that not only the presence of peers is important, but also the behavior and characteristics of these peers, including their age, gender and their own involvement in delinquency, deviance and substance use. An individual involved in unstructured socializing with lawabiding peers who never use substances, may still not be likely to use alcohol or drugs himself or herself.

Finally, the negative consequences of substance may also depend on the conditions in which substances are used, but very little is yet known about the differential long-term effects of where, when and with whom substances are used (Freisthler et al. 2014).

To conclude, whereas previous research had empirically demonstrated that adolescents often involved in unstructured socializing are more likely to use substances, the present research has shown that indeed substance use typically occurs during unstructured socializing, and that each of the components of unstructured socializing-unstructured activity, peer presence and authority absence-uniquely provokes substance use independently from the other components. The findings may help parents, teachers, counselors and policy makers who aim to prevent adolescent substance use, to direct some of their efforts to changing the situations that adolescents encounter during their daily activities. Often times, situations are easier to change than people.

Acknowledgements We thank Stijn Ruiter and Jeroen Weesie for advice on draft versions, Gerben Bruinsma, Evelien Hoeben, Kirsten Grandia, Lieven Pauwels and Frank Weerman for managing and coordinating data collection, and Per-Olof Wikström for sharing the space-time budget measurement instrument. We thank three anonymous reviewers of this journal for helpful comments and recommendations. Data collection was supported by the Netherlands Organization for Scientific Research (NWO), Grant Number 431-09-021.

Open Access This article is distributed under the terms of the Creative Commons Attribution 4.0 International License (http://creativecommons.org/licenses/by/4.0/), which permits unrestricted use, distribution, and reproduction in any medium, provided you give appropriate credit to the original author(s) and the source, provide a link to the Creative Commons license, and indicate if changes were made.

\section{Appendix}

See Tables 4, 5 and 6. 
Table 4 List of unstructured (marked '*') and structured (not marked '*') activities

\begin{tabular}{|c|c|c|c|}
\hline$*$ & School break & & Retail/sales work \\
\hline$*$ & Hanging around & & Catering work \\
\hline$*$ & Walking/biking around & & Hospitality service work \\
\hline$*$ & Socialize & & Engineering/electronics work \\
\hline$*$ & Talking face to face & & Motor vehicle work \\
\hline$*$ & Talking by phone & & Hairdressing work \\
\hline$*$ & Communication by e-mail etc. & & Manufacturing work \\
\hline$*$ & Texting & & Office work \\
\hline$*$ & Partying & & Care and health work \\
\hline$*$ & Sexual activity & & Boxing \\
\hline$*$ & Night clubbing in bar/club & & Martial arts \\
\hline$*$ & Going to a birthday party & & Tennis \\
\hline$*$ & Socialize and drink & & Badminton \\
\hline$*$ & Multiway socializing & & Table-tennis \\
\hline$*$ & Visiting someone & & Athletics \\
\hline \multirow[t]{9}{*}{$*$} & Attending a wedding & & Other individual sports \\
\hline & General domestic activity & & Rugby \\
\hline & Housework/Chores & & Football \\
\hline & Gardening & & Cricket \\
\hline & Shopping (domestic) & & Ice-hockey \\
\hline & Child care not paid & & Land-hockey \\
\hline & Pet care & & Basketball \\
\hline & Walking the dog & & Volleyball \\
\hline & Other incl. cooking (fun) & & Korfball/handball \\
\hline \multirow[t]{24}{*}{ \# } & Shopping (fun) & & Other team sports \\
\hline & Eating & & Drama \\
\hline & Personal care (washing, dressing) & & Dance, music, orchestra, band \\
\hline & Medical care (treatment etc.) & & Art/photography/multimedia \\
\hline & Ill at home & & Guides/scouts \\
\hline & Dental care & & Church/mosque/religious center \\
\hline & Physical exercise & & Other specific club/organization \\
\hline & Psychological treatment & \# & Hobbies and games general \\
\hline & Praying & \# & Hobbies (collect, paint, write) \\
\hline & School classes and lectures & \# & Roller/Ice-skating/skateboarding \\
\hline & Homework & \# & Bowling \\
\hline & Other school based & \# & Darts \\
\hline & Apprenticeship, internship & \# & Snooker \\
\hline & Application interview & \# & Traditional game playing \\
\hline & Going home ill & & Gymnastics \\
\hline & Work general/other (paid) & & Ballet \\
\hline & Voluntary work & & Street dance, breakdance, etc. \\
\hline & Agricultural work & & Horse riding \\
\hline & Newspaper round (work) & $\#$ & Travel main activity \\
\hline & Cleaning work & & Cultural activity general \\
\hline & Sales employee (work) & & Official meeting \\
\hline & Fitness & & Watching sports event \\
\hline & Collect items (to go) & & Visit barber, beauty salon \\
\hline & Construction work & & Cleaning up room/bed \\
\hline
\end{tabular}

Activities marked \# were included as 'unstructured' in the robustness check discussed in footnote 8 
Table 5 Fixed effects logistic regression estimates of substance use. Model FE4

\begin{tabular}{|c|c|c|c|c|}
\hline \multirow[t]{2}{*}{ Variables } & \multicolumn{4}{|c|}{ Model FE4 } \\
\hline & B & SE & OR & $p^{\mathrm{a}}$ \\
\hline Unstructured activities & 1.581 & 0.190 & 4.862 & 0.000 \\
\hline Presence of peers & 1.304 & 0.183 & 3.685 & 0.000 \\
\hline Absence of authority figure(s) & 0.512 & 0.233 & 1.669 & 0.028 \\
\hline Weekend & 1.311 & 0.109 & 3.711 & 0.000 \\
\hline \multicolumn{5}{|l|}{ Interactions $^{\mathrm{b}}$} \\
\hline Night time & 2.522 & 0.120 & 12.454 & 0.000 \\
\hline Unstructured $\times$ Peers & -0.155 & 0.225 & 0.857 & 0.492 \\
\hline Unstructured $\times$ Authority & 0.321 & 0.206 & 1.379 & 0.119 \\
\hline Peers $\times$ Authority & 0.258 & 0.251 & 1.294 & 0.304 \\
\hline Hours & 14,665 & & & \\
\hline Individuals & 229 & & & \\
\hline Log likelihood & -1698 & & & \\
\hline AIC & 3413 & & & \\
\hline
\end{tabular}

Unstructured $=$ Unstructured activities; Authority $=$ Absence of authority figures

${ }^{a} p$ values two-sided

${ }^{\mathrm{b}}$ No Bonferroni corrections on interaction terms 


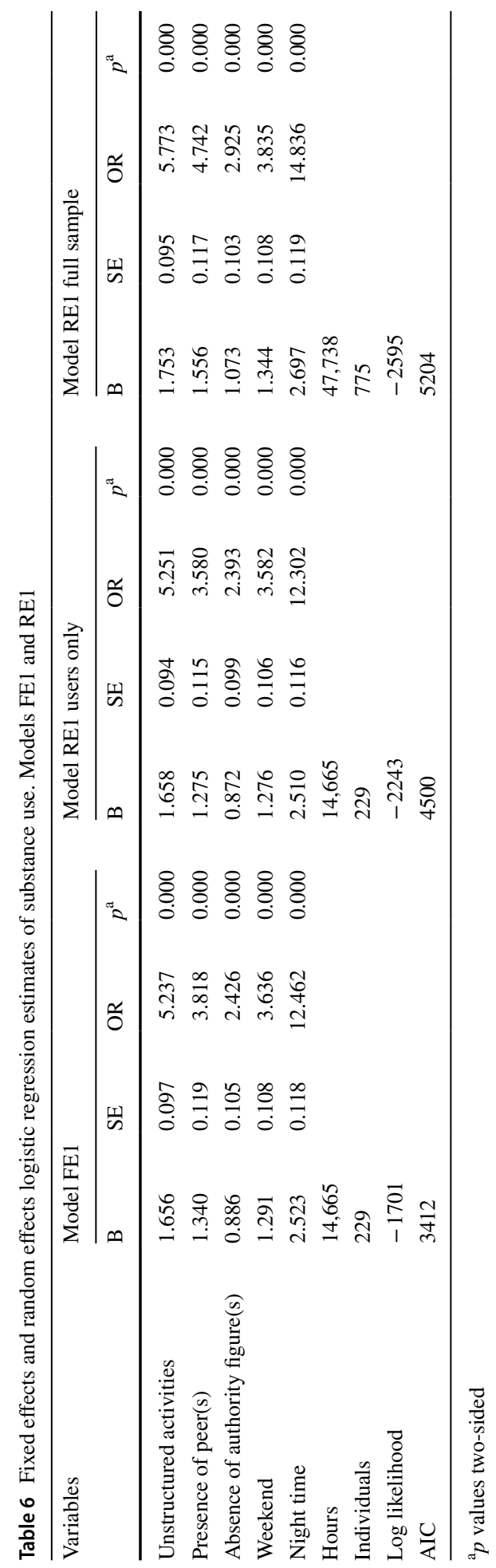




\section{References}

Anderson AL (2003) An opportunity model of juvenile delinquency. Pennsylvania State University. Retrieved from https://etda.libraries.psu.edu/files/final_submissions/201

Anderson AL, Hughes LA (2009) Exposure to situations conducive to delinquent behavior: the effects of time use, income, and transportation. J Res Crime Delinq 46(1):5-34. https://doi.org/10.1177/00224 27808326587

Augustyn MB, McGloin JM (2013) The risk of informal socializing with peers: considering gender differences across predatory delinquency and substance use. Justice Q 30(1):117-143. https://doi. org/10.1080/07418825.2011.597417

Averdijk M, Bernasco W (2015) Testing the situational explanation of victimization among adolescents. J Res Crime Delinq 52(2):151-180. https://doi.org/10.1177/0022427814546197

Barnes GM, Hoffman JH, Welte JW, Farrell MP, Dintcheff BA (2007) Adolescents' time use: effects on substance use, delinquency and sexual activity. J Youth Adolesc 36(5):697-710. https://doi.org/10.1007/ s10964-006-9075-0

Baron RM, Kenny DA (1986) The moderator-mediator variable distinction in social psychological research: conceptual, strategic, and statistical considerations. J Personal Soc Psychol 51(6):1173-1182. https:// doi.org/10.1037/0022-3514.51.6.1173

Behrendt S, Wittchen HU, Höfler M, Lieb R, Beesdo K (2009) Transitions from first substance use to substance use disorders in adolescence: Is early onset associated with a rapid escalation? Drug Alcohol Depend. https://doi.org/10.1016/j.drugalcdep.2008.06.014

Beier H (2018) Situational peer effects on adolescents' alcohol consumption: the moderating role of supervision, activity structure, and personal moral rules. Deviant Behav 39(3):363-379. https://doi. org/10.1080/01639625.2017.1286173

Bernasco W, Ruiter S, Bruinsma GJN, Pauwels LJR, Weerman FM (2013) Situational causes of offending: a fixed-effects analysis of space-time budget data. Criminology 51(4):895-926. https://doi. org/10.1111/1745-9125.12023

Bjerk D (2009) How much can we trust causal interpretations of fixed-effects estimators in the context of criminality? J Quant Criminol. https://doi.org/10.1007/s10940-009-9073-y

Bond R (2005) Group size and conformity. Group Process Intergroup Relat 8(4):331-354. https://doi. org/10.1177/1368430205056464

Brantingham PL, Brantingham PJ (1993) Environment, routine, and situation: toward a pattern theory of crime. In: Clarke RV, Felson M (eds) Routine activity and rational choice. Transaction Publishers, New Brunswick, pp 259-294. https://doi.org/10.4324/9781315128788-12

Brechwald WA, Prinstein MJ (2011) Beyond homophily: a decade of advances in understanding peer influence processes. J Res Adolesc 21(1):166-179. https://doi.org/10.1111/j.1532-7795.2010.00721.x

Brüderl J, Ludwig V (2015) Fixed-effects panel regression. In: Best H, Wolf C (eds) Regression analysis and causal inference. Sage, Los Angeles, pp 327-357. https://doi.org/10.1017/CBO9781107415324.004

Cohen LE, Felson M (1979) Social change and crime rate trends: a routine activity approach. Am Sociol Rev 44(4):588-608

Cornish DB, Clarke RV (eds) (1986) The Reasoning criminal: rational choice perspectives on offending. Springer, New York, NY

Demers A (1997) When at risk? Drinking contexts and heavy drinking in the Montreal adult population. Contemp Drug Probl 24(3):449-471. https://doi.org/10.1177/009145099702400303

Demers A, Kairouz S, Adlaf E, Gliksman L, Newton-Taylor B, Marchand A (2002) Multilevel analysis of situational drinking among Canadian undergraduates. Soc Sci Med 55(3):415-424. https://doi. org/10.1016/S0277-9536(01)00258-1

Flannery DJ, Williams LL, Vazsonyi AT (1999) Who are they with and what are they doing? Delinquent behavior, substance use, and early adolescents' after-school time. Am J Orthopsychiatry 69(2):247253. https://doi.org/10.1037/h0080426

Flay BR, Petraitis J (2003) Bridging the gap between substance use prevention theory and practice. In: Sloboda Z, Bukoski WJ (eds) Handbook of drug abuse prevention. Springer, Berlin, pp 289-305. https:// doi.org/10.1007/0-387-35408-5

Freisthler B, Lipperman-Kreda S, Bersamin M, Gruenewald PJ (2014) Tracking the when, where, and with whom of alcohol use integrating ecological momentary assessment and geospatial data to examine risk for alcohol-related problems. Alcohol Res Curr Rev 36(1):29-38

Gibbs JP (1981) Norms, deviance, and social control: conceptual matters. Elsevier, New York

Gilligan C, Kypri K (2012) Parent attitudes, family dynamics and adolescent drinking: qualitative study of the Australian parenting guidelines for adolescent alcohol use. BMC Public Health 12(1):1-11. https:// doi.org/10.1186/1471-2458-12-491 
Gmel G, Rehm J, Kuntsche E (2003) Binge drinking in Europe: definitions, epidemiology, and consequences. Sucht 49(2):105-116

Halaby CN (2004) Panel models in sociological research: theory into practice. Ann Rev Sociol 30(1):507544. https://doi.org/10.1146/annurev.soc.30.012703.110629

Hawdon JE (1999) Daily routines and crime: using routine activities as measures of Hirschi's involvement. Youth Soc 30(4):395-415. https://doi.org/10.1177/0044118X99030004001

Hirschi T (1969) Causes of delinquency. University of California Press, Berkely

Hoeben EM (2016) Hanging out and messing about: elaborating on the relationship between unstructured socializing and adolescent delinquency. Ridderprint, Amsterdam

Hoeben EM, Weerman F (2014) Situational conditions and adolescent offending: Does the impact of unstructured socializing depend on its location? Eur J Criminol 11(4):481-499. https://doi. org/10.1177/1477370813509346

Hoeben EM, Bernasco W, Weerman FM, Pauwels L, van Halem S (2014) The space-time budget method in criminological research. Crime Sci 3:1-15. https://doi.org/10.1186/s40163-014-0012-3

Hoeben EM, Meldrum RC, Walker D, Young JTN (2016) The role of peer delinquency and unstructured socializing in explaining delinquency and substance use: a state-of-the-art review. J Crim Justice 47:108-122. https://doi.org/10.1016/j.jcrimjus.2016.08.001

Hussong AM (2000) The settings of adolescent alcohol and drug use. J Youth Adolesc 29(1):107-119

Hussong AM (2002) Differentiating peer contexts and risk for adolescent substance use. J Youth Adolesc. https://doi.org/10.1023/A:1015085203097

Janssen MM, Mathijssen JJP, van Bon-Martens MJH, van Oers HAM, Garretsen HFL (2014) A qualitative exploration of attitudes towards alcohol, and the role of parents and peers of two alcohol-attitudebased segments of the adolescent population. Subst Abuse Treat Prev Policy 9(1):1-10. https://doi. org/10.1186/1747-597X-9-20

Kairouz S, Gliksman L, Demers A, Adlaf EM (2002) For all these reasons, I do... drink: A multilevel analysis of contextual reasons for drinking among Canadian undergraduates. J Stud Alcohol 63(5):600-608. https://doi.org/10.15288/jsa.2002.63.600

King KM, Chassin L (2007) A prospective study of the effects of age of initiation of alcohol and drug use on young adult substance dependence*. J Stud Alcohol Drugs 68(2):256-265. https://doi.org/10.15288 /jsad.2007.68.256

Kirke DM (2004) Chain reactions in adolescents' cigarette, alcohol and drug use: Similarity through peer influence or the patterning of ties in peer networks? Soc Netw 26(1):3-28. https://doi.org/10.1016/j. socnet.2003.12.001

Kypri K, Dean JI, Stojanovski E (2007) Parent attitudes on the supply of alcohol to minors. Drug Alcohol Rev 26(1):41-47. https://doi.org/10.1080/09595230601037018

Loeber R, Farrington DP (2014) Age-crime curve. In: Bruinsma G, Weisburd D (eds) Encyclopedia of criminology and criminal justice. Springer, Berlin, pp 12-18. https://doi.org/10.1007/978-1-4614-5690-2

Lynskey MT, Heath AC, Bucholz KK, Slutske WS, Madden PAF, Nelson EC, Statham DJ, Martin NG (2003) Escalation of drug use in early-onset cannabis users vs co-twin controls. JAMA 289(4):427433. https://doi.org/10.1001/jama.289.4.427

Meldrum RC, Clark J (2015) Adolescent virtual time spent socializing with peers, substance use, and delinquency. Crime Delinq 61(8):1104-1126. https://doi.org/10.1177/0011128713492499

Miller J (2013) Individual offending, routine activities, and activity settings : revisiting the routine activity theory of general deviance. J Res Crime Delinq 50(3):390-416. https://doi.org/10.1177/0022427811 432641

Moon DG, Hecht ML, Jackson KM, Spellers RE (1999) Ethnic and gender differences and similarities in adolescent drug use and refusals of drug offers. Subst Use Misuse 34(8):1059-1083. https://doi. org/10.3109/10826089909039397

Osgood DW, Wilson JK, O’Malley PMO, Bachman JG, Johnston LD (1996) Routine activities and individual deviant behavior. Am Sociol Rev 61(4):635-655

Pervin LA (1978) Definitions, measurements, and classifications of stimuli, situations, and environments. Hum Ecol 6(1):71-105. https://doi.org/10.1007/BF00888567

Petraitis J, Flay BR, Miller TQ (1995) Reviewing theories of adolescent substance use: organizing pieces in the puzzle. Psychol Bull 117(1):67-86. https://doi.org/10.1037/0033-2909.117.1.67

Raja SN, McGee R, Stanton WR (1992) Perceived attachments to parents and peers and psychological wellbeing in adolescence. J Youth Adolesc 21(4):471-485. https://doi.org/10.1007/BF01537898

Schulz F, Grunow D (2012) Comparing diary and survey estimates on time use. Eur Sociol Rev 28(5):622632. https://doi.org/10.1093/esr/jcr030

Simons-Morton B, Pickett W, Boyce W, ter Bogt TFM, Vollebergh W (2010) Cross-national comparison of adolescent drinking and cannabis use in the United States, Canada, and the Netherlands. Int J Drug Policy 21(1):64-69. https://doi.org/10.1016/j.drugpo.2009.02.003 
Svensson R, Pauwels L (2010) Is a risky lifestyle always "risky"? The interaction between individual propensity and lifestyle risk in adolescent offending: a test in two urban samples. Crime Delinq 56(4):608626. https://doi.org/10.1177/0011128708324290

Terry-McElrath YM, O'Malley PM, Johnston LD (2013) Simultaneous alcohol and marijuana use among US high school seniors from 1976 to 2011: trends, reasons, and situations. Drug Alcohol Depend. https://doi.org/10.1016/j.drugalcdep.2013.05.031

Thorlindsson T, Bernburg JG (2006) Peer groups and substance use: examinong the direct and interactive effect of leisure activity. Adolescence 41(162):321-339

van der Gaag RS, Herlitz L, Hough M (2019) Contemporary challenges in school recruitment for criminological survey research: lessons from the international self-report delinquency study in England, Germany, the Netherlands, and the United States. J Contemp Crim Justice. https://doi.org/10.1177/10439 86219870940

Vazsonyi AT, Pickering LE, Belliston LM, Hessing D, Junger M (2002) Routine activities and deviant behaviors: American, Dutch, Hungarian, and Swiss youth. J Quant Criminol 18(4):397-422. https:// doi.org/10.1023/A:1021121727676

Vega WA, Aguilar-Gaxiola S, Andrade L, Bij1 R, Borges G, Caraveo-Anduaga JJ, DeWit DJ, Heeringa SG, Kessler RC, Kolody B, Wittchen H-U (2002) Prevalence and age of onset for drug use in seven international sites: results from the international consortium of psychiatric epidemiology. Drug Alcohol Depend 68(3):285-297. https://doi.org/10.1016/S0376-8716(02)00224-7

Warr M (1993) Age, peers, and delinquency. Criminology 31(1):17-40. https://doi. org/10.1111/j.1745-9125.1993.tb01120.x

Warr M (2002) Companions in crime: the social aspects of criminal conduct. Cambridge University Press, Cambridge

Weerman FM, Bernasco W, Bruinsma GJN, Pauwels LJR (2015) When Is spending time with peers related to delinquency? The importance of where, what, and with whom. Crime Delinq 61(10):1386-1413. https://doi.org/10.1177/0011128713478129

Werch C, Moore M, DiClemente CC, Owen DM, Jobli E, Bledsoe R (2003) A sport-based intervention for preventing alcohol use and promoting physical activity among adolescents. J Sch Health 73(10):380388. https://doi.org/10.1111/j.1746-1561.2003.tb04181.x

Werch C, Moore MJ, DiClemente CC, Bledsoe R, Jobli E (2005) A multihealth behavior intervention integrating physical activity and substance use prevention for adolescents. Prev Sci. https://doi. org/10.1007/s11121-005-0012-3

Wikstrom P-OH, Butterworth DA (2006) Adolescent crime: individual differences and lifestyles. Willan Publishing, Collumpton

Wikström P-OH, Ceccato V, Hardie B, Treiber K (2010) Activity fields and the dynamics of crime: advancing knowledge about the role of the environment in crime causation. J Quant Criminol 26(1):55-87. https://doi.org/10.1007/s10940-009-9083-9

Wikstrom P-OH, Oberwittler D, Treiber K, Hardie B (2012) Breaking rules: the social and situational dynamics of young people's urban crime. Oxford University Press, Oxford

Wikström P-OH, Mann RP, Hardie B (2018) Young people's differential vulnerability to criminogenic exposure: bridging the gap between people- and place-oriented approaches in the study of crime causation. Eur J Criminol 15(1):10-31. https://doi.org/10.1177/1477370817732477

Publisher's Note Springer Nature remains neutral with regard to jurisdictional claims in published maps and institutional affiliations. 